\title{
CYPC19*17 POLYMORPHISM AS A RISK-FACTOR FOR NSAIDS-INDUCED ULCERS
}

\author{
Serhiy Tkach \\ Ukrainian Scientifically Practical Center of Endocrine Surgery Ministry of Health of Ukraine \\ 13 A Klovsky descent, Kyiv, Ukraine, 01021 \\ tkachsergio@yahoo.com \\ Lyudmyla Onischuk \\ Department of internal medicine \#1 \\ Bogomolets National Medical University \\ 17 Shevchenko blvd., Kyiv, Ukraine, 01601 \\ lyudmila.onishhuk@mail.ru \\ Alexandra Balabanseva \\ S. I. Georgievsky Crimea State Medical University \\ 69 Kyivska str., Simferopol
}

\begin{abstract}
The new risk-factors for peptic ulcers induced by the use of nonsteroidal antiinflammatory drugs, such as polymorphism of different isoenzymes of cytochrome P450 were considered in the article. The aim of the research was to study different genetic polymorphism of several ferments CYP2C9 and CYP2C19 in inclination to NSAIDS-gastropathies by the way of estimation the risk of appearance of Helicobacter pylori (HP)-positive or Hp-negative NSAIDS- induced peptic ulcers, complicated or not with upper gastrointestinal bleeding.

124 persons were examined (76 men, 48 women in the age of 56,2+/-9,1 years) with Hp-positive or Hp-negative NSAIDS-induced peptic ulcers, that were performed genotyping of isoferments of cytochrome system (CYP2C9, CYP2C19). Based on investigations of 5 different isoenzymes (CYP 2C9*2, CYP 2C9*3, CYP 2C19*2, CYP 2C19*3 and CYP 2C19*17). It was founded that peptic ulcers are strictly associated only with CYP 2C19*17-genotype, possibly due to its involvement in arachidonic acid metabolism and gastroprotection. Thus, polymorphism CYP $2 \mathrm{C} 19^{*} 17$ can be considered as one of the risk factors for NSAID-gastropathy though the future researches are needed.
\end{abstract}

Keywords: NSAID gastropathy, risk factors, CYP 2C19 polymorphism.

\section{Background}

Nonsteroidal anti-inflammatory drugs (NSAIDs)-is one of highly used drugs, taken by 30 million of people every day.

The popularity and high use of NSAIDs is explained by their significant analgetic and anti-inflammatory effect in treatment of arthritis and other acute or chronic diseases of muscloskeletal system and pain syndroms of differnet genesis [1-3]. Un fortunately, use of NSAIDs is essentially restricted because of adverse effects (AE), such as gastropathyes, firstly.

NSAIDs-gastropathies are erosive ulcerative affects of gastroduodenal zone, that appear during the use of NSAIDs and aspirin and have a specific cilinic an endoscopic picture.Their diagnostic criteries are chronologic connection with the usage of NSAIDs, the lack of symptoms, blurring clincal picture, the high risk of bleeding manifistation, acute and often numerous injuries, preferred location in antral part of a stomach, the absence of inflammatory wave around the ulcers, foveolar hyperplasia of mucose and quite quick healing, when NSAIDs cancelled. Gastroduodenal toxity is explained by the block of production of cytoprotective prostanoids, intermediated with the 1st type of cyclooxygenase, such as prostaglandin E2 and prostacyclin. High selective ingibitors of the 2nd type of cyclooxygenase provoke less expressed injuries of gastroduodenal zone, than non-selective NSAIDs, that inhibit the 1st type of cyclooxygenase and the 2nd type of cyclooxygenase as well. But they don't solve the hole problem [4-6]. 
This problem is extremely actual, as long as the number of hospatalisations and deathes, connected with the usage of NSAIDs and economical expenses for curing NSAIDs-gastropathies grow every year. Ulcers and bleeding, inducted with the usage of NSAIDs still remain one of the most important problems of the internal medicine. Thus, for the information from the different sorces, near $25-40 \%$ of chronic users of NSAIDs have got erosion and peptic ulcers of gastroduodenal zone. And $2-4 \%$ of patients have got bleedings and perforations, that cause bad effect. Rick related bleeding manifstation, perforation and death as a result of NSAIDs-induced ulcers made accordingly 3,6 and 7,6 [2,6]. The states, connected with the usage of NSAIDs make a great contribution in common number of morbidity and mortality in many contries all over the world. For example, in USA adverse effects of the usage of NSAIDs are the 15th often cause of mortality. And in common, $30 \%$ of patients, taking NSAIDs have got gastrointestinal AE even if ulcers are absent. In Great Britain among 18000 of hospitalised patients NSAIDs were the main class of drugs, casing AE (in $30 \%$ of patients), and NSAIDs-induced ulcers and bleedings were the cause of $61 \%$ of deathes, connectsd to AE of drugs [6].

Ulcerous anamnesis( relative risk=13,5), usage of several NSAIDs, including aspirin (relative risk $=9,0$ ), usage of high doses of NSAIDs (relative risk=7,0), usage of anticoagulants (relative risk=6,4), age under 70 (relative risk=5,6), usage of corticosteroids (relative risk=2,2), Helicobacter pylory infection $(\mathrm{Hp})$ are used to be generally acknowledged as a risk of development of gastropathies [2, 7-9]. Unfortunately, many other factors of risk, that influence an appearance of NSAIDs-gastropathies are not well learned, because of inconsistent information from differant sources of information. In particular, terms of appearance of gastrointestinal AE and complications, farmakokinetics of used NSAIDs, and what part of gastrointestinal tract is mostly affected, frequency of AE development in different rheumathologic pathology, consequences of usage of NSAIDs with a long period of excretion( retard forms). There are only several works about frequency and evidence AE of usage of NSAIDs and the effectiveness of therapy according to polymorphism of different isoenzymes of hepatic cytochrome P450 (CYP2C8, CYP2C9, CYP2C19) system, that is responsible for metabolism of many drugs [10-14].

The family of cytochrome CYP2C includes $20 \%$ of hepatic maintenance of CYP450 and metabolises $25-30 \%$ of often used drugs such as NSAIDs, Inhibitors of proton pomp (IPP), antidepressants, benzodiasepines and clopidogrel [1, 15-18]. It's important, that isoenzymes CYP2C also metabolise endogenous substance, such as arachidonum acid and estrogens [19]. Three representatives of the family CYP2C (CYP2C8, CYP2C9, CYP2C19) are highly polymorphic isoenzymes and have numerous mononucleotide polymorphism (MNP) with different frequency in different ethnic populations [20-22]. Today 14 CYP2C8-, 35 CYP2C9-, 28 CYP2C19-coding (MNP) are well known, some of which are clinically important, as they can essentially change metabolism of different drugs.

Previous researches showed people with MNP in genes, coding enzymes that metabolise NSAIDs, to have a higher risk of development of peptic ulcers and/or upper gastrointestinal bleeding (GIB), although the results were quite disputable [1, 6, 10, 11, 16, 23]. Performed systematic review on this problem showed, that in presence it's very difficult to evaluate if there is an interaction between effects of NSAIDs and presence of coding variants of basic NSAIDs-metabolising systems of cytochrome P450, such as CYP2C9, CYP2C8, CYP2C19 and also if these variants raise the risk of NSAIDs-gastropathies development not depending on each other [10-14].

Quite recently MNP in family CYP2C19 (CYP2C19*17) was detected to cause inclination to appearance of peptic ulcers by the way of changing of IPP metabolism [16, 18, 24, 25].

\section{The aim of research}

To study the different genetic polymorphism of several enzymes CYP2C9 and CYP2C19 in inclination to NSAIDS-gastropathies by the way of estimation of possible connection between some clinically important MNP and the risk of appearance of Helicobacter pylori (HP)-positive or Hp-negative NSAIDS- induced peptic ulcers, complicated or not with the upper GIB . 


\section{Materials and methods}

124 persons were examined (76 men, 48 women in the age of 56,2+/-9,1 years old) with Hp-positive or Hp-negative NSAIDS-induced peptic ulcers, that underwent genotyping of isoenzymes of cytochrome system (CYP2C9, CYP2C19). All patients underwent upper endoscopy and detection of HP-status with the help of 13C-urea test.

All patients were divided into 2 groups:

1) patients with endoscopy proved peptic ulcers (64 person), appeared during 2 weeks-intake of NSAIDS;

2) patients without peptic ulcers (60 person, that either take NSAIDS (38 person), or not (22 person) before endoscopy.

To NSAIDS-users were ascribed people, who take this medicine at least for a week or more in period of 2 weeks before endoscopy.

Among 124 patients peptic ulcers were endoscopy verified in 64 patients ( $51,6 \%$ ), including $82,3 \%$ of patients with NSAIDS intake and $17,7 \%$ of patients without it. And 60 patients $(48,4 \%)$ didn't have any endoscopy substantiation of peptic ulcers $(63,3 \%$ of them take NSAIDS and $36,7 \%$ didn't). Among the patients with peptic ulcers 20 patients $(31,3 \%)$, with NSAIDS-intake and $4(6,6 \%)$ ones had upper GIB. $81,3 \%$ patients with peptic ulcers and 66,6 \% person without them were Hp-infected. There are clinical and demographic characteristics of patients with peptic ulcers (PU) or without them in Table 1.

\section{Table 1}

Clinical and demographic characteristic of patients.

\begin{tabular}{|c|c|c|}
\hline Characteristics & Patients with PU $(n=64)$ & Patients without $\mathrm{PU}(\mathrm{n}=60)$ \\
\hline Average age $(+/-)$ & $53.1(7.8)$ & $58.3(7.5)$ \\
\hline Men, n (\%) & $46(71.9)$ & $30(50)$ \\
\hline $\begin{array}{c}\text { Endoscopic indication, } \mathrm{n}(\%) \\
\text { Melena } \\
\text { Dispeptic syndrome/ abdominal pain }\end{array}$ & $\begin{array}{l}20(31.1 \%) \\
25(39.1 \%)\end{array}$ & $\begin{array}{c}2(3.3 \%) \\
28(46.6 \%)\end{array}$ \\
\hline $\begin{array}{l}\text { Anemia } \\
\text { Reflux symptoms } \\
\text { Others }\end{array}$ & $\begin{aligned} 12 & (15.6 \%) \\
5 & (4.9 \%) \\
2 & (3.1 \%)\end{aligned}$ & $\begin{array}{l}6(10 \%) \\
12(20 \%) \\
12(20 \%)\end{array}$ \\
\hline $\mathrm{Hp}+, \mathrm{n}(\%)$ & $52(81.3 \%)$ & $41(66.6 \%)$ \\
\hline Smoking, n (\%) & $31(46.8 \%)$ & $26(43.3 \%)$ \\
\hline Alcohol abuse, $\mathrm{n}(\%)$ & $14(21.9 \%)$ & $11(18.3)$ \\
\hline NSAIDS-intake & $64(100 \%)$ & $38(63.3 \%)$ \\
\hline Low doze of aspirin & $23(35.9 \%)$ & $12(31.6 \%)$ \\
\hline Diclofenac & $25(39.1 \%)$ & $14(36.8 \%)$ \\
\hline Ibuprofen & $2(4.7 \%)$ & $5(13.2 \%)$ \\
\hline Coxibes & $13(20.3 \%)$ & $7(18.4 \%)$ \\
\hline \multicolumn{3}{|l|}{ Concomitant therapy, $\mathrm{n}(\%)$} \\
\hline IPP & $48(75 \%)$ & $7(11.7 \%)$ \\
\hline Antitrombocyte medicines & $12(18.8 \%)$ & $3(5 \%)$ \\
\hline Steroids & $4(63 \%)$ & $1(1.7 \%)$ \\
\hline \multicolumn{3}{|l|}{ Clinical anamnesis, $\mathrm{n}(\%)$} \\
\hline Duodenal ulcer & $11(17.2 \%)$ & $7(11.7 \%)$ \\
\hline Gastric ulcer & $4(6.3 \%)$ & $1(1.7 \%)$ \\
\hline GIB & $8(12.5 \%)$ & $2(3.4 \%)$ \\
\hline Cardiovascular pathology & $22(34.4 \%)$ & $21(35 \%)$ \\
\hline Cerebrovascular pathology & $17(26.6 \%)$ & $18(30 \%)$ \\
\hline Respiratory diseases & $6(9.4 \%)$ & $5(8.3 \%)$ \\
\hline Muscle and skeletal problems & $12(18.8 \%)$ & $10(16.6 \%)$ \\
\hline Diabetes & $5(7.8 \%)$ & $5(8.3 \%)$ \\
\hline
\end{tabular}

Genotyping was performed after separation of genome DNA from the solid blood with addition of EDTA with the help of multiplex polymerase chain reaction (PCR) with fluorescent scheme 
of detection of products in Real time "SNP-EXPRESS-SHOT" - PB with the use of test-systems LOTECH CYP2C9 and CYP3C19 ACE (S. Petersburg, Russian). According to the data of genotyping, such variants of polymorphism of cytochrome CYP2C9 were detected: CYP2C9*2 (rs 1799853) and CYP2CP*3 (rs1057910), and also such variants of polymorphism of cytochrome 2C19 as CYP2C19*2 (rs4244285), CYP2C19*3 (rs4986893) and CYP2C19*17 (rs12248560). Depending on genotype 2C19 examined patients could be ascribed to the group of extremely fast metabolisers of IPP (genotype *1/*17), fast metabolisers of IPP (genotype *1/*1), moderately fast metabolisers of IPP (genotype $* 1 / * 2, * 1 / * 3$ ) or slow metabolisers of IPP (genotype $* 2 / * 2, * 2 / * 3, * 3 / * 3$ ).

\section{The results of research}

According to the data of the Table 2, with the help of logistic regressive analysis, only one MNP, CYP2C19*17 appeared to be noticeably connected with PU (correlation of chance (CC)-1.45; $95 \%$ confidence interval (CI)-1.14 to $1.90 ; \mathrm{P}=0.005$ ). No positive connection between learned $\mathrm{CY}-$ P2C-genotypes and NSAIDS, also between H. pylori status (negative or positive) was found. Possibly because of not large excerpt of patients.

Table 2

Analysis of connection between learned polymorphisms of CYP2C9 and CYP2C19 and presence of peptic ulcers

\begin{tabular}{|c|c|c|c|c|c|}
\hline \multirow[t]{2}{*}{ MNP } & \multirow[t]{2}{*}{ Reference MNP } & \multicolumn{4}{|c|}{ Analysis of connection with presence of $P U$} \\
\hline & & $\mathbf{n}$ & $\mathbf{P}$ & $\mathbf{C C}$ & $95 \%$ CI \\
\hline CYP2C9*2 & rs1799853 & 124 & 0.83 & 0.96 & $0.69-1.35$ \\
\hline CYP2C9*3 & rs1057910 & 122 & 0.76 & 0.94 & $0.63-1.40$ \\
\hline CYP2C19*2 & rs4244285 & 123 & 0.91 & 1.02 & $0.74-1.41$ \\
\hline CYP19*3 & rs4986893 & 123 & 0.86 & 0.92 & $0.71-1.36$ \\
\hline CYPC19*17 & rs12248560 & 122 & 0.005 & $1 / 45$ & $1.14-1.90$ \\
\hline
\end{tabular}

A big part of patients with PU was notified among carriers of variant allele CYP2C19*17 $(1 * / 17-71,7 \% ; 17 * / 17 *-21,9 \%$, variants CT and TT accordingly comparatively to homozygotes of such type $\left(1 * / 1^{*}-6,4 \% ; \mathrm{P}=0,024\right.$ with the use of $\mathrm{X} 2 \mathrm{n}$ text). Analysis of sensitivity, that was performed in patients without $\mathrm{Hp}$-infection, didn't show the confident connection with genotype CYP2C19*17 comparing with patients with or without PU $(\mathrm{P}=0.062)$ or patients with or without upper GIB $(\mathrm{P}=0,63)$.

\section{Discussion of results}

Unlike the other previous researches in our work, we have studied the role of five different genetic polymorphisms of isoenzymes CYP2C9 and CYP2C19 in inclination to NSAIDS-gastropathies, particularly to development of NSAIDS-induced peptic ulcers and upper GIB. The received results didn't show any connection between polymorphism CYP2C9*2, CYP2C9*3, CYP2C19*2, CYP2C19*3 and NSAIDS-induced peptic ulcers and upper GIB. Nevertheless, we've noticed connection between the allele of CYP2C*17 and presence of PU in all allele and genotype levels, independently on affect of NSAIDS and the presence of Hp-infection. The further analysis, taking into account all of CYP2C19-genotypes and the presence of PU (with the use of genotype *1/*1 as initial base) showed only genotype $* 1 / * 17$ to be connected to PU noticeably.

Why CYP2C19*17 is connected to Pu isn’t clear enough, although there are several explanations. As CYP2C19*17 is known to be a spread polymorphism with amplification of function, carriers of which have a higher index of metabolism of some clinically important medicines (such as IPP, escitolopram, sertrallin, clopidogrel and other), with further decrease of their concentration in plasma and extenuation of clinical effect $[7,15,16,18,20,24,26-30]$. Nevertheless, the review of functional and clinical consequences of carrying of allele CYP2C19*17 made a conclusion, that it has only insignificant effect, that hardly would be clinically important, besides homozygotes CYP2C19*17, and only for medicines with narrow therapeutic window [18, 24, 28]. On the other hand, there were made conclusion in some recent researches, that carrying of allele CYP2C19*17 
in patients, taking clopidogrel is associated with lower reactivity of thrombocytes, decrease of the risk of cardiovascular diseases and thrombosis of the stent, but with the higher risk of intensive bleedings $[30,31]$. So one of the possible explanation of noticed connection may be the fact, that carriers of CYP2C19*17 accelerate metabolism and decline clinical effectiveness of IPP, and decline gastroprotective possibility of mucosa to resist to aggressive factors( for example, NSAIDS and H. pylori) and incline to appearance of PU in that way.

Besides, isoenzymes CYP2C take part not only in metabolism of xenobiotics, but different endogen substances [18, 21, 22]. For example, arachidonic acid in 4 types epoxyeikosatrien acids (EETA)-5,6-EETA, 8,9-EETA, 11-12-EETA and 14,15-EETA, that are known to be species and organ specific and have different physiological functions ( including control of vascular tonus, angiogenesis, migration of cells, proliferation and inflammation) [19]. Although, the role of EETA in human gastrointestinal tract isn't studied thoroughly, they are considered to inhibit production of prostoglandine E2 in the cells of unstriated muscles and take part in formation of active forms of oxygen in endothelial cells of vessels, that can cause ischemic dysfunctions [19, 23, 25]. So one of the possible explanations of the connection between PU and CYP2C19*17 can be that the last one changes metabolism of arachidonic acid, and as a result, protective features of Gastroduodenal mucosa decrease because of lower rate of production of gastroprotective prostaglandine E2 and amplification of vasoconstriction in microcirculatory circle of mucosa and production of active damaging forms of oxygen $[25,32]$.

\section{Conclusion}

So, our research showed, that the presence of allele CYP2C19*17 has confident connection with endoscopic proved NSAIDS-induced PU and may be considered as a factor of the risk of NSAIDS-gastropathy development. Possible biological explanation of the found association may be participation of isoenzyme CYP2C19 in metabolism of arachidonic acid that is known to take part in gastroprotection and pathogenesis of PU. Patients with polymorphism CYP2C19 have not only the higher risk of development of NSAIDS-induced peptic ulcers, but faster metabolism of IPP, that significantly decrease their clinical effectiveness and make healing of ulcers lower. To prove our conclusions and more deeply estimate functional consequences about affect of polymorphism CYP2C19*17 on pathogenesis of PU, further researches in different populations and with more quantity of patients should be done.

\section{References}

[1] Baldwin, R. M., Ohlsson, S., Pedersen, R. S., Mwinyi, J., Ingelman-Sundberg, M., Eliasson, E., Bertilsson, L. (2008). Increased omeprazole metabolism in carriers of the CYP2C19*17 allele; a pharmacokinetic study in healthy volunteers. British Journal of Clinical Pharmacology, 65 (5), 767-774. doi: 10.1111/j.1365-2125.2008.03104.x

[2] Bhatt, D. L., Scheiman, J., Abraham, N. S., Antman, E. M., Chan, F. K. L., Furberg, C. D. et. al (2008). ACCF/ACG/AHA 2008 Expert Consensus Document on Reducing the Gastrointestinal Risks of Antiplatelet Therapy and NSAID Use. The American Journal of Gastroenterology, 103 (11), 2890-2907. doi: 10.1111/j.15720241.2008.02216.x

[3] Blanco, G., Martínez, C., Ladero, J. M., Garcia-Martin, E., Taxonera, C., Gamito, F. G. et. al (2008). Interaction of CYP2C8 and CYP2C9 genotypes modifies the risk for nonsteroidal anti-inflammatory drugs-related acute gastrointestinal bleeding. Pharmacogenetics and Genomics, 18 (1), 37-43. doi: 10.1097/ fpc.0b013e3282f305a9

[4] Carbonell, N., Verstuyft, C., Massard, J., Letierce, A., Cellier, C., Deforges, L. et. al (2010). CYP2C9*3 Loss-of-Function Allele Is Associated With Acute Upper Gastrointestinal Bleeding Related to the Use of NSAIDs Other Than Aspirin. Clinical Pharmacology \& Therapeutics, 87 (6), 693-698. doi: 10.1038/clpt.2010.33

[5] Chan, F. K. L. (2005). NSAID-Induced Peptic Ulcers and Helicobacter pylori Infection. Drug Safety, 28 (4), 287-300. doi: 10.2165/00002018-200528040-00002

[6] Estany-Gestal, A., Salgado-Barreira, A., Sánchez-Diz, P., Figueiras, A. (2011). Influence of CYP2C9 genetic variants on gastrointestinal bleeding associated with nonsteroidal anti-inflammatory drugs. Pharmacogenetics and Genomics, 21 (7), 357-364. doi: 10.1097/fpc.0b013e328346d2bb 
[7] Goldstein, J. A. (2001). Clinical relevance of genetic polymorphisms in the human CYP2C subfamily. British Journal of Clinical Pharmacology, 52 (4), 349-355. doi: 10.1046/j.0306-5251.2001.01499.x

[8] Harmsze, A. M., van Werkum, J. W., Hackeng, C. M., Ruven, H. J. T., Kelder, J. C., Bouman, H. J. et. al (2012). The influence of CYP2C19*2 and *17 on on-treatment platelet reactivity and bleeding events in patients undergoing elective coronary stenting. Pharmacogenetics and Genomics, 22 (3), 169-175. doi: $10.1097 / \mathrm{fpc} .0 \mathrm{~b} 013 \mathrm{e} 32834 \mathrm{ff} 6 \mathrm{e} 3$

[9] Hunfeld, N. G., Mathot, R. A., Touw, D. J., van Schaik, R. H., Mulder, P. G., Franck, P. F. et. al. (2008). Effect of CYP2C19 $* 2$ and $* 17$ mutations on pharmacodynamics and kinetics of proton pump inhibitors in Caucasians. British Journal of Clinical Pharmacology, 65 (5), 752-760. doi: 10.1111/j.1365-2125. 2007.03094.x

[10] Hunt, R. H., Lanas, A., Stichtenoth, D. O., Scarpignato, C. (2009). Myths and facts in the use of anti-inflammatory drugs. Annals of Medicine, 41 (6), 423-437. doi: 10.1080/07853890902887295

[11] Ingelman-Sundberg, M., Sim, S. C., Gomez, A., Rodriguez-Antona, C. (2007). Influence of cytochrome P450 polymorphisms on drug therapies: Pharmacogenetic, pharmacoepigenetic and clinical aspects. Pharmacology \& Therapeutics, 116 (3), 496-526. doi: 10.1016/j.pharmthera.2007.09.004

[12] Kaspera, R., Totah, R. A. (2009). Epoxyeicosatrienoic acids: formation, metabolism and potential role in tissue physiology and pathophysiology. Expert Opinion on Drug Metabolism \& Toxicology, 5 (7), 757-771. doi: 10.1517/17425250902932923

[13] Li-Wan-Po, A., Girard, T., Farndon, P., Cooley, C., Lithgow, J. (2010). Pharmacogenetics of CYP2C19: functional and clinical implications of a new variant CYP2C19*17. British Journal of Clinical Pharmacology, 69 (3), 222-230. doi: 10.1111/j.1365-2125.2009.03578.x

[14] Ma, J., Yang, X. Y., Qiao, L., Liang, L. Q., \& Chen, M. H. (2008). CYP2C9 polymorphism in non-steroidal anti-inflammatory drugs-induced gastropathy. Journal of Digestive Diseases, 9 (2), 79-83. doi: 10.1111/j.17512980.2008.00326.x

[15] Malfertheiner, P., Megraud, F., O’Morain, C. A., Atherton, J., Axon, A. T. R., Bazzoli, F. et. al (2012). Management of Helicobacter pylori infection--the Maastricht IV/ Florence Consensus Report. Gut, 61 (5), 646-664. doi: 10.1136/gutjnl-2012-302084

[16] McNamara, D. (2004). Gastro-oesophageal reflux disease and ulcer disease in Europe: NSAID-related gastroduodenal pathology. The Burden of Gastrointestinal Diseases in Europe, 31-36.

[17] Micklewright, R., Lane, S., Linley, W., McQuade, C., Thompson, F., Maskrey, N. (2003). NSAIDs, gastroprotection and cyclo-oxygenase-II-selective inhibitors*. Alimentary Pharmacology and Therapeutics, 17 (3), 321-332. doi: 10.1046/j.1365-2036.2003.01454.x

[18] Musumba, C. O., Jorgensen, A., Sutton, L., Van Eker, D., Zhang, E., O’Hara, N. et. al (2012). CYP2C19*17 Gain-of-Function Polymorphism Is Associated With Peptic Ulcer Disease. Clinical Pharmacology \& Therapeutics, 93 (2), 195-203. doi: 10.1038/clpt.2012.215

[19] Musumba, C., Pritchard, D. M., Pirmohamed, M. (2009). Review article: cellular and molecular mechanisms of NSAID-induced peptic ulcers. Alimentary Pharmacology \& Therapeutics, 30 (6), 517-531. doi: 10.1111/j.1365-2036.2009.04086.x

[20] Musumba, C., Jorgensen, A., Sutton, L., Eker, D., Moorcroft, J., Hopkins, M. et. al (2012). The relative contribution of NSAIDs and Helicobacter pylori to the aetiology of endoscopically-diagnosed peptic ulcer disease: observations from a tertiary referral hospital in the UK between 2005 and 2010. Alimentary Pharmacology \& Therapeutics, 36 (1), 48-56. doi: 10.1111/j.1365-2036.2012.05118.x

[21] Pedersen, R. S., Brasch-Andersen, C., Sim, S. C., Bergmann, T. K., Halling, J., Petersen, M. S. et. al (2010). Linkage disequilibrium between the CYP2C19*17 allele and wildtype CYP2C8 and CYP2C9 alleles: identification of CYP2C haplotypes in healthy Nordic populations. European Journal of Clinical Pharmacology, 66 (12), 1199-1205. doi: 10.1007/s00228-010-0864-8

[22] Pilotto, A., Seripa, D., Franceschi, M., Scarcelli, C., Colaizzo, D., Grandone, E. et. al (2007). Genetic Susceptibility to Nonsteroidal Anti-Inflammatory Drug-Related Gastroduodenal Bleeding: Role of Cytochrome P450 2C9 Polymorphisms. Gastroenterology, 133 (2), 465-471. doi: 10.1053/j.gastro.2007.05.025

[23] Rosemary, J., Adithan, C. (2007). The Pharmacogenetics of CYP2C9 and CYP2C19: Ethnic Variation and Clinical Significance. Current Clinical Pharmacology, 2 (1), 93-109. doi: 10.2174/ 157488407779422302 
[24] Scarpignato, C., Hunt, R. H. (2010). Nonsteroidal Antiinflammatory Drug-Related Injury to the Gastrointestinal Tract: Clinical Picture, Pathogenesis, and Prevention. Gastroenterology Clinics of North America, 39 (3), 433-464. doi: 10.1016/j.gtc.2010.08.010

[25] Scott, S. A., Martis, S., Peter, I., Kasai, Y., Kornreich, R., Desnick, R. J. (2011). Identification of CYP2C19*4B: pharmacogenetic implications for drug metabolism including clopidogrel responsiveness. The Pharmacogenomics Journal, 12 (4), 297-305. doi: 10.1038/tpj.2011.5

[26] Scott, S. A., Sangkuhl, K., Shuldiner, A. R., Hulot, J.-S., Thorn, C. F., Altman, R. B., Klein, T. E. (2012). PharmGKB summary. Pharmacogenetics and Genomics, 22 (2), 159-165. doi: 10.1097/fpc.0b013e32834d4962

[27] Scott, S. A., Sangkuhl, K., Gardner, E. E., Stein, C. M., Hulot, J.-S., Johnson, J. A. et. al (2011). Clinical Pharmacogenetics Implementation Consortium Guidelines for Cytochrome P450-2C19 (CYP2C19) Genotype and Clopidogrel Therapy. Clinical Pharmacology \& Therapeutics, 90 (2), 328-332. doi: 10.1038/ clpt.2011.132

[28] Shiotani, A., Sakakibara, T., Yamanaka, Y., Nishi, R., Imamura, H., Fujita, M. et. al (2009). The preventive factors for aspirin-induced peptic ulcer: aspirin ulcer and corpus atrophy. Journal of Gastroenterology, 44 (7), 717-725. doi: 10.1007/s00535-009-0068-0

[29] Sibbing, D., Gebhard, D., Koch, W., Braun, S., Stegherr, J., Morath, T. (2010). Isolated and interactive impact of common CYP2C19 genetic variants on the antiplatelet effect of chronic clopidogrel therapy. Journal of Thrombosis and Haemostasis, 8 (8), 1685-1693. doi: 10.1111/j.1538-7836.2010.03921.x

[30] Vergara, M., Catalan, M., Gisbert, J. P., Calvet, X. (2005). Meta-analysis: role of Helicobacter pylori eradication in the prevention of peptic ulcer in NSAID users. Alimentary Pharmacology and Therapeutics, 21 (12), 1411-1418. doi: 10.1111/j.1365-2036.2005.02444.x

[31] Yasar, U., Lundgren, S., Eliasson, E., Bennet, A., Wiman, B., de Faire, U., Rane, A. (2002). Linkage between the CYP2C8 and CYP2C9 genetic polymorphisms. Biochemical and Biophysical Research Communications, 299 (1), 25-28. doi: 10.1016/s0006-291x(02)02592-5

[32] Zabalza, M., Subirana, I., Sala, J., Lluis-Ganella, C., Lucas, G., Tomas, M. et. al (2011). Meta-analyses of the association between cytochrome CYP2C19 loss- and gain-of-function polymorphisms and cardiovascular outcomes in patients with coronary artery disease treated with clopidogrel. Heart, 98 (2), 100-108. doi: 10.1136/hrt.2011.227652 